\title{
Moderate-term reproducibility of heart rate variability during rest and light to moderate exercise in children
}

\author{
A.S. Leicht ${ }^{1}$ and G.D. Allen ${ }^{2}$ \\ ${ }^{1}$ Institute of Sport and Exercise Science, James Cook University, Townsville, Queensland, Australia \\ ${ }^{2}$ Centre for the Assessment of Human Performance, University of Southern Queensland, Toowoomba, \\ Australia
}

Correspondence to: A. Leicht, Institute of Sport and Exercise Science, James Cook University, Townsville, QLD 4811, Australia

Fax: +61-7-4781-6688. E-mail: anthony.leicht@jcu.edu.au

\begin{abstract}
Previous studies have demonstrated the high reproducibility of heart rate variability (HRV) measures in adults while little information exists concerning HRV reproducibility in children. Subsequently, the aim of the current study was to examine the moderate-term reproducibility of heart rate and frequency domain measures of HRV during rest and light to moderate exercise in children. Ten healthy children ( 6 males, 4 females) aged between 7 and 12 years of age volunteered for this study with HRV recordings obtained during supine rest and three treadmill walking exercise work rates ( $\leq 60 \%$ maximum heart rate), initially and then 8 weeks later. Differences $(P<0.05)$ between variables were examined using paired $t$-tests or Wilcoxon signed rank tests while reliability and reproducibility were examined by intraclass correlation coefficients (ICC), coefficients of variation (CV), and mean bias ratio and ratio limits of agreement (LOA). Heart rate and all measures of HRV at rest and exercise were unchanged after 8 weeks. Significant ICC were documented primarily during rest $(0.72-0.85)$ while weaker relationships $(-0.02-0.87)$ were evident during exercise. A large range of CV was identified during rest (6-33\%) and exercise (3-128\%) while the ratio LOA were variable and substantial (1.04-2.73). Despite similar HRV over an 8-week period, variable ICC and sizable CV and ratio LOA indicate moderate to poor reproducibility of HRV in children, particularly during light to moderate exercise. Studies examining $\mathrm{HRV}$ in children should include age- or maturation stage-matched control participants to address the age-related change in HRV and inadequate HRV reliability.
\end{abstract}

Key words: Autonomic nervous system; Heart rate; Parasympathetic; Neural control; Reliability

Part of this study has been previously presented at the 2007 European Congress of Sport Sciences, 11-14th July, Jyvaskyla, Finland.

Received November 23, 2007. Accepted June 13, 2008

\section{Introduction}

Since the early 1980's, an extensive number of studies has examined heart rate (HR) function and fluctuations over time. Akselrod and colleagues (1) reported that HR fluctuations in dogs resulted from the influence of the parasympathetic and sympathetic nervous systems on the sino-atrial node at various frequencies. Similarly, the normal HR fluctuations or heart rate variability (HRV) in humans have been demonstrated to reflect the autonomic control of HR $(2,3)$. Several HRV frequency components have been identified via power spectral analysis to characterize the neural control of HR: very low frequency oscillations $(<0.04 \mathrm{~Hz})$ reflecting vasomotor, renin-angiotensin and parasympathetic modulations $(1,4)$, low frequency oscillations $(0.04-0.15 \mathrm{~Hz})$ reflecting parasympathetic and sympathetic modulations including the baroreflex, and high frequency oscillations $>0.15 \mathrm{~Hz}$ reflecting parasympathetic modulations, including respiratory influences $(2,3)$. As a non-invasive measure of autonomic control of $\mathrm{HR}, \mathrm{HRV}$ has been incorporated into screening protocols for the prediction of mortality following myocardial infarction (5) 
as well as an indicator of future risk for cardiac events in healthy adults (6). Standard guidelines for the measurement of HRV have been developed; however, the reproducibility of HRV has been highlighted as an important area for further examination $(7,8)$.

Kleiger et al. (9) reported that HRV was similar and reproducible $(r>0.8)$ up to 65 days between recordings in healthy adults. Others have reported similar reproducibility for short- and long-term HRV recordings in adults, $24 \mathrm{~h}$ (10), $48 \mathrm{~h}$ (11), 1-2 weeks (12-15), 2-6 months (16) and 624 months $(3,17)$ apart. The majority of studies examining HRV reproducibility have investigated adults, with very few studies examining HRV reproducibility in children. In recent times, Winsley and colleagues (18) examined HRV during rest and light exercise in children, concluding that short-term HRV reproducibility as measured by the coefficient of variation (CV, 31-187\%) was poor in children despite similar HRV measurements. This study did not state the time frame between HRV recordings and therefore it is difficult to apply these results to other HRV studies with children. Further, studies examining HRV in children have demonstrated significant differences in HRV with age $(19,20)$, disease $(20)$ and exercise training $(21,22)$, demonstrating the growing interest in HRV and children. On this basis, a better understanding of HRV reproducibility in children is warranted. Therefore, the aim of the current study was to examine the reproducibility of HRV during rest and light to moderate exercise over a time frame typically utilised during intervention studies such as exercise training (i.e., 8 weeks).

\section{Material and Methods}

\section{Participants}

Ten healthy, active children volunteered for this study. All participants were pre-pubertal as determined from interviews with parents and children and none had exercised regularly for at least 3 months prior to commencement of the study. All completed the PAR-Q (23) and a general health and lifestyle pre-screening questionnaire to confirm their healthy status. Each participant was familiarized with the testing equipment and procedures used in the laboratory and provided informed written consent along with guardian's informed written consent prior to participation. The study was approved by the institutional Human Ethics Research Committee.

\section{Procedure}

Participants arrived at the laboratory between 6-10 am in a fasted ( $\geq 12 \mathrm{~h}$ ) and rested (no exercise in the prior 24$36 \mathrm{~h})$ state. Upon arrival, body mass was determined and
EKG monitoring electrodes (3M Pty Ltd., USA) applied for the recording of modified $\mathrm{V}_{1}$ and $\mathrm{V}_{5}$ leads. EKG recordings were then obtained using a Marquette Holter Monitor 8500 (Marquette Electronics Inc., USA) and stored on an audio cassette tape (TDK AD60, TDK USA Corp., USA) for later analysis. Participants rested in the supine position for 46 min with the final 16 min analysed for resting HRV. During rest, participants lay on a bench with minimal noise and body movement and were visually monitored to ensure wakefulness. A 30-min period was utilised to ensure the attainment and stabilisation of resting HR (24). Breathing rate was not controlled as previous studies have reported similar HRV and vagal modulation during spontaneous and controlled breathing over typical breathing rates of $7.5-20$ breaths/min $(25,26)$.

Following rest, continuous walking at three different exercise work rates was performed by participants on a motor driven treadmill (Quinton Model 24-72, Quinton Instrument Co., USA). The speed and inclination of the treadmill were altered to obtain the following work rates: lowest treadmill work rate $(2 \mathrm{~km} / \mathrm{h}$ at $0 \%$ incline; Ex1) and work rates that elevated HR to approximately 50\% (Ex2) and $60 \%$ (Ex3) of age-predicted maximum HR (23). Each work rate lasted $10 \mathrm{~min}$ and included the recording of exercise HRV during steady state.

Following the initial session, participants returned to the laboratory at the same time of the day, 8 weeks later for the determination of HRV as previously described (i.e., supine rest and exercise at the same three absolute work rates). An 8-week timeframe was chosen as it reflects a typical time period utilised for intervention studies such as exercise training $(24,27)$.

\section{Heart rate variability analysis}

Tapes with HR recordings were analysed on a commercially available Holter analysis system (Marquette Series 8000, v002A software, Marquette Electronics Inc., USA) for HRV as previously described (24). Briefly, 2-min power spectra were analysed for frequency domain measurements of HRV using a 256-point Radix 2 FFT and Hanning window. Three frequency components were examined in each power spectrum: low frequency (LF) $0.041-$ $0.15 \mathrm{~Hz}$ modulations of the sympathetic and parasympathetic nervous systems; high frequency (HF) $0.15-0.40 \mathrm{~Hz}$ representing parasympathetic modulations, and total power (TP) $0-0.40 \mathrm{~Hz}$, an index primarily reflecting parasympathetic modulations $(3,7)$. Very low frequency modulations $(<0.04 \mathrm{~Hz})$ were not examined in the current study as longer recordings are recommended for the analysis of this HRV component (7). The LF, HF and TP components were expressed in absolute units $\left(\mathrm{ms}^{2} / \mathrm{Hz}\right)$ while the $\mathrm{LF}$ and $\mathrm{HF}$ 
components were also expressed in normalized units (nu) and as a ratio (LF/HF) as indices of sympathovagal balance (3).

\section{Statistical analysis}

Data were analysed using SPSS v14 (SPSS Inc., USA). Data normality was examined using the KolmogorovSmirnov statistic with a Lilliefors correction. When the normality assumption was violated, data were transformed using a natural logarithm prior to further statistical analysis. Differences in mass and HRV variables between the two sessions were determined by paired $t$-tests and Wilcoxon signed rank tests, where appropriate. Reliability was determined by intraclass correlation coefficients (ICC) with $95 \%$ confidence intervals, while reproducibility was examined from the calculation of the CV (average SD of differences $x \sqrt{ }(1-I C C) /$ average mean) and mean bias (mean difference between values) with $95 \%$ limits of agreement (LOA, $\pm 1.96 \times$ SD of differences between values) $(28,29)$. As heteroscedastic errors (i.e., positive correlations between measurement differences and means) were identified for some of the variables, all variables were transformed (i.e., natural logarithmic) prior to calculation of the measurement bias ratio * $\div$ ratio LOA (30). The measurement bias ratio provides a dimensionless number that indicates the level of agreement between measurements with a value of one indicating perfect agreement. Similar to the $\mathrm{CV}$, the ratio LOA indicates the spread of measurements with $95 \%$ of observed ratios within the ratio LOA\% of the mean bias. For example, a measurement bias ratio of $0.98 * / \div 1.06$ indicates little bias (i.e., close to perfect agreement $=$ one) with $95 \%$ of all ratios for this variable within $6 \%$ of the mean measurement bias ratio (30). All data are reported as mean \pm SEM. A P < 0.05 was deemed to be significant for all analyses.

\section{Results}

Compared to the initial session, body mass was significantly greater 8 weeks later as a result of mass increases for the oldest male and female participants (Table 1). During rest and exercise, HR and all HRV measures were similar between sessions (Table 2). Significant ICC for HR and HRV meas-
Table 1. Characteristic of all participants.

\begin{tabular}{lcccc}
\hline \multirow{2}{*}{ Participant } & \multirow{2}{*}{ Gender } & Age (years) & \multicolumn{2}{c}{ Mass $(\mathrm{kg})$} \\
\cline { 4 - 5 } & & & 0 weeks & 8 weeks \\
\hline \multirow{2}{n}{} & & & 25.1 & 25.7 \\
2 & Male & 7 & 26.5 & 26.6 \\
3 & Male & 9 & 33.0 & 33.3 \\
4 & Male & 10 & 25.3 & 25.4 \\
5 & Male & 11 & 44.8 & 45.5 \\
6 & Male & 11 & 56.8 & 60.1 \\
7 & Male & 12 & 23.3 & 23.7 \\
8 & Female & 7 & 37.5 & 38.3 \\
9 & Female & 8 & 53.0 & 53.3 \\
10 & Female & 9 & 45.2 & 47.7 \\
Mean & Female & 11 & 37.0 & 37.9 \\
SEM & & 9.5 & 3.9 & 4.1 \\
\hline
\end{tabular}

Table 2. Heart rate and heart rate variability measures at 0 and 8 weeks.

\begin{tabular}{|c|c|c|c|c|}
\hline & Rest & Ex1 & Ex2 & Ex3 \\
\hline \multicolumn{5}{|l|}{ HR (bpm) } \\
\hline 0 weeks & $69.7 \pm 3.3$ & $98.6 \pm 3.7$ & $107.8 \pm 1.6$ & $124.4 \pm 1.4$ \\
\hline 8 weeks & $68.3 \pm 3.4$ & $99.3 \pm 3.5$ & $108.3 \pm 1.1$ & $126.1 \pm 2.2$ \\
\hline \multicolumn{5}{|c|}{$\mathrm{HR}\left(\% \mathrm{HR}_{\max }\right)$} \\
\hline 0 weeks & - & $46.8 \pm 1.7$ & $50.8 \pm 0.6$ & $59.5 \pm 0.8$ \\
\hline 8 weeks & - & $47.1 \pm 1.6$ & $51.4 \pm 0.5$ & $59.8 \pm 1.1$ \\
\hline \multicolumn{5}{|l|}{$\mathrm{LF}\left(\mathrm{ms}^{2} / \mathrm{Hz}\right)$} \\
\hline 0 weeks & $5424 \pm 1137$ & $873 \pm 226$ & $520 \pm 161$ & $122 \pm 23$ \\
\hline 8 weeks & $4570 \pm 1088$ & $993 \pm 322$ & $477 \pm 130$ & $110 \pm 16$ \\
\hline \multicolumn{5}{|l|}{ LF (nu) } \\
\hline 0 weeks & $53.7 \pm 2.8$ & $61.4 \pm 3.8$ & $67.0 \pm 3.1$ & $55.7 \pm 5.3$ \\
\hline 8 weeks & $52.4 \pm 3.4$ & $62.8 \pm 3.9$ & $63.4 \pm 5.1$ & $54.3 \pm 4.9$ \\
\hline \multicolumn{5}{|c|}{$\mathrm{HF}\left(\mathrm{ms}^{2} / \mathrm{Hz}\right)$} \\
\hline 0 weeks & $4283 \pm 807$ & $553 \pm 173$ & $208 \pm 63$ & $75 \pm 17$ \\
\hline 8 weeks & $3629 \pm 742$ & $688 \pm 311$ & $328 \pm 177$ & $78 \pm 24$ \\
\hline \multicolumn{5}{|l|}{$\mathrm{HF}(\mathrm{nu})$} \\
\hline 0 weeks & $45.6 \pm 2.8$ & $36.0 \pm 3.7$ & $29.2 \pm 1.8$ & $35.5 \pm 3.9$ \\
\hline 8 weeks & $46.9 \pm 3.1$ & $34.3 \pm 3.5$ & $32.8 \pm 4.6$ & $34.0 \pm 3.0$ \\
\hline \multicolumn{5}{|l|}{$\mathrm{TP}\left(\mathrm{ms}^{2} / \mathrm{Hz}\right)$} \\
\hline 0 weeks & $15663 \pm 2774$ & $2482 \pm 459$ & $1402 \pm 274$ & $803 \pm 95$ \\
\hline 8 weeks & $13560 \pm 2529$ & $2973 \pm 950$ & $1819 \pm 614$ & $790 \pm 58$ \\
\hline \multicolumn{5}{|l|}{ LF/HF } \\
\hline 0 weeks & $1.5 \pm 0.2$ & $2.3 \pm 0.6$ & $2.6 \pm 0.3$ & $1.9 \pm 0.4$ \\
\hline 8 weeks & $1.4 \pm 0.2$ & $2.3 \pm 0.3$ & $2.5 \pm 0.5$ & $1.9 \pm 0.4$ \\
\hline
\end{tabular}

Data are reported as means \pm SEM. Ex1 $=$ lowest treadmill work rate of $2 \mathrm{~km} / \mathrm{h}$ at $0 \%$ incline; Ex2 = work rate that elevated HR to approximately $50 \%$ of agepredicted maximum heart rate; Ex3 = work rate that elevated HR to approximately $60 \%$ of age-predicted maximum heart rate; $\mathrm{HR}=$ heart rate; $\mathrm{bpm}=$ beats per minute; $\mathrm{HR}_{\max }=$ age predicted maximum heart rate; $\mathrm{LF}=$ low frequency; $\mathrm{HF}=$ high frequency; TP = total power; nu = normalized units. 
ures, reflecting substantial to excellent reliability (10), were demonstrated, primarily at rest (Table 3 ). Across the 8week period, the $\mathrm{CV}$ ranged between 6.0 and $32.8 \%$ for resting HRV measures and between 3.0 and $128.2 \%$ for exercise HRV measures (Table 4). Similar to the CV, the measurement bias ratio and $95 \%$ ratio LOA for HR and HRV measures were also large and variable, particularly for HRV measures expressed in $\mathrm{ms}^{2} / \mathrm{Hz}$ (Table 5). An example of the variability during rest and Ex1 is shown for $\mathrm{HR}, \mathrm{HF}\left(\mathrm{ms}^{2}\right), \mathrm{HF}(\mathrm{nu})$, and LF/HF in Figure 1. Variability (i.e., spread of the data points was greater) increased when HRV was expressed in absolute units $\left(\mathrm{ms}^{2} / \mathrm{Hz}\right)$ and during exercise (Ex1).

\section{Discussion}

The results of the current study demonstrated that in prepubertal children, HR and HRV measures during rest and light to moderate exercise were not significantly altered over 8 weeks. Significant ICC confirmed this similarity across 8 weeks for resting HRV measures; however, weaker relationships and greater confidence intervals were demonstrated for most of the HRV measures during light to moderate exercise. Despite the similarity in HRV measures across 8 weeks, large CV and ratio LOA (i.e., ratios up to $273 \%$ different) indicated large intra-individual variation and reproducibility for moderate-term studies of HRV in children.

Table 3. Intraclass correlation coefficients ( $95 \%$ confidence intervals) for heart rate and heart rate variability measures from 0 to 8 weeks.

\begin{tabular}{|c|c|c|c|c|}
\hline & Rest & Ex1 & Ex2 & Ex3 \\
\hline $\mathrm{HR}$ (bpm) & $0.85(0.50 \text { to } 0.96)^{* * *}$ & $0.83(0.47 \text { to } 0.96)^{\star *}$ & $-0.07(-0.71$ to 0.62$)$ & $0.48(-0.28$ to 0.87$)$ \\
\hline $\mathrm{LF}\left(\mathrm{ms}^{2} / \mathrm{Hz}\right)$ & $0.86(0.53 \text { to } 0.96)^{\star \star *}$ & $0.32(-0.35$ to 0.77$)$ & $0.27(-0.49$ to 0.79$)$ & $0.40(-0.37$ to 0.84$)$ \\
\hline LF (nu) & $0.85(0.51 \text { to } 0.96)^{* * *}$ & $0.34(-0.33$ to 0.78$)$ & $0.56(-0.17$ to 0.89$)$ & $0.87(0.49 \text { to } 0.97)^{* *}$ \\
\hline $\mathrm{HF}\left(\mathrm{ms}^{2} / \mathrm{Hz}\right)$ & $0.72(0.21 \text { to } 0.92)^{\star *}$ & $0.23(-0.43$ to 0.73$)$ & $-0.02(-0.68$ to 0.66$)$ & $0.85(0.42 \text { to } 0.97)^{* *}$ \\
\hline $\mathrm{HF}(\mathrm{nu})$ & $0.84(0.49 \text { to } 0.96)^{\star * *}$ & $0.18(-0.48$ to 0.71$)$ & $0.32(-0.44$ to 0.81$)$ & $0.78(0.22 \text { to } 0.95)^{* *}$ \\
\hline $\mathrm{TP}\left(\mathrm{ms}^{2} / \mathrm{Hz}\right)$ & $0.75(0.27 \text { to } 0.93)^{* *}$ & $0.44(-0.22$ to 0.83$)$ & $-0.03(-0.68$ to 0.65$)$ & $0.13(-0.59$ to 0.73$)$ \\
\hline LF/HF & $0.83(0.46 \text { to } 0.96)^{\star *}$ & $0.28(-0.38$ to 0.76$)$ & $0.69(0.05 \text { to } 0.93)^{*}$ & $0.80(0.28 \text { to } 0.96)^{\star *}$ \\
\hline
\end{tabular}

Ex1 = lowest treadmill work rate of $2 \mathrm{~km} / \mathrm{h}$ at $0 \%$ incline; Ex2 = work rate that elevated $\mathrm{HR}$ to approximately $50 \%$ of age-predicted maximum heart rate; $\mathrm{Ex} 3=$ work rate that elevated $\mathrm{HR}$ to approximately $60 \%$ of age-predicted maximum heart rate; $\mathrm{HR}=$ heart rate; $\mathrm{bpm}=$ beats per minute; $\mathrm{LF}=$ low frequency; $\mathrm{HF}=$ high frequency; $\mathrm{TP}=$ total power; $\mathrm{nu}=$ normalized units.

${ }^{*} \mathrm{P}<0.05 ;{ }^{* *} \mathrm{P}<0.01 ;{ }^{* * *} \mathrm{P}<0.001$.

Table 4. Coefficient of variation (\%) for heart rate and heart rate variability measures from 0 to 8 weeks.

\begin{tabular}{lrrrr}
\hline & Rest & Ex1 & Ex2 & Ex3 \\
\hline HR $(\mathrm{bpm})$ & 6.0 & 4.7 & 3.7 & 3.0 \\
LF $\left(\mathrm{ms}^{2} / \mathrm{Hz}\right)$ & 26.4 & 76.5 & 70.7 & 37.7 \\
LF $(\mathrm{nu})$ & 7.1 & 16.0 & 11.7 & 9.3 \\
HF $\left(\mathrm{ms}^{2} / \mathrm{Hz}\right)$ & 32.8 & 108.2 & 128.2 & 29.0 \\
HF $(\mathrm{nu})$ & 8.1 & 29.6 & 24.2 & 13.3 \\
TP $\left(\mathrm{ms}^{2} / \mathrm{Hz}\right)$ & 28.8 & 60.9 & 79.1 & 25.3 \\
LF/HF & 19.5 & 49.9 & 24.2 & 24.7 \\
\hline
\end{tabular}

Ex1 $=$ lowest treadmill work rate of $2 \mathrm{~km} / \mathrm{h}$ at $0 \%$ incline; Ex2 = work rate that elevated HR to approximately $50 \%$ of age-predicted maximum heart rate; Ex3 $=$ work rate that elevated $\mathrm{HR}$ to approximately $60 \%$ of age-predicted maximum heart rate; $\mathrm{HR}=$ heart rate; $\mathrm{bpm}=$ beats per minute; $\mathrm{LF}=$ low frequency; $\mathrm{HF}=$ high frequency; $\mathrm{TP}=$ total power; $\mathrm{nu}=$ normalized units.
Table 5. Measurement bias ratio * $\div \div 95 \%$ ratio limits of agreement for heart rate and heart rate variability measures from 0 to 8 weeks.

\begin{tabular}{lcccc}
\hline & Rest & Ex1 & Ex2 & Ex3 \\
\hline $\mathrm{HR}(\mathrm{bpm})$ & $1.02 * / \div 1.10$ & $0.99 * / \div 1.07$ & $0.99 * / \div 1.06$ & $0.99 * / \div 1.04$ \\
$\mathrm{LF}\left(\mathrm{ms}^{2} / \mathrm{Hz}\right)$ & $1.25 * / \div 1.69$ & $1.06 * / \div 2.09$ & $1.05 * / \div 1.90$ & $1.10 * / \div 1.68$ \\
$\mathrm{LF}(\mathrm{nu})$ & $1.03 * / \div 1.12$ & $0.98 * / \div 1.27$ & $1.07 * / \div 1.22$ & $1.03 * / \div 1.14$ \\
$\mathrm{HF}\left(\mathrm{ms}^{2} / \mathrm{Hz}\right)$ & $1.21 * / \div 1.64$ & $1.13 * / \div 2.58$ & $0.92 * / \div 2.73$ & $1.06 * / \div 1.65$ \\
$\mathrm{HF}(\mathrm{nu})$ & $0.97 * / \div 1.11$ & $1.04 * / \div 1.51$ & $0.94 * / \div 1.36$ & $1.03 * / \div 1.22$ \\
TP $\left(\mathrm{ms}^{2} / \mathrm{Hz}\right)$ & $1.17 * / \div 1.68$ & $0.99 * / \div 1.76$ & $0.88 * / \div 2.04$ & $0.99 * / \div 1.42$ \\
LF/HF & $1.05 * / \div 1.29$ & $0.93 * / \div 1.92$ & $1.15 * / \div 1.67$ & $1.00 * / \div 1.41$ \\
\hline
\end{tabular}

$\mathrm{HR}=$ heart rate; $\mathrm{bpm}=$ beats per minute; $\mathrm{LF}=$ low frequency; $\mathrm{HF}=$ high frequency; $\mathrm{TP}=$ total power; nu $=$ normalized units. Ex1 $=$ lowest treadmill work rate of $2 \mathrm{~km} / \mathrm{h}$ at $0 \%$ incline; Ex2 = work rate that elevated HR to approximately $50 \%$ of age-predicted maximum heart rate; $\mathrm{Ex} 3=$ work rate that elevated $\mathrm{HR}$ to approximately $60 \%$ of age-predicted maximum heart rate. 
Previous studies have examined both short-term (2-10 min) and long-term (24 h) HRV recordings in adults and concluded that HRV was highly reproducible for up to 365 days, particularly at rest $(3,11,13,15,17)$. Most prior studies have examined changes in mean HRV and/or ICC $(3,15,17)$ as reliability measures. As demonstrated in the current study, these measures may not accurately reflect the biological variation and have been suggested to poorly reflect reproducibility $(17,28,29)$. The current study examined more appropriate reproducibility measures such as the CV and ratio LOA $(8,28-30)$ and demonstrated large biological variation over the 8-week period. Such variation may be related to the length of HRV recording with greater reproducibility reported with longer HRV recording length (e.g., $24 \mathrm{~h}$ ) compared to shorter recordings $(13,31)$. In comparing 10-s, 2- and 6-min HRV recordings, Schroeder and colleagues (13) demonstrated that the repeatability of HRV measures from 2-min recordings was excellent and similar to those from 6-min recordings. Therefore, HRV reproducibility of the 2-min recordings in the current study is unlikely to be a result of recording length, but rather a result of the younger population and/or greater HRV. Greater 95\% confidence interval for HRV measures in young individuals compared to older persons (32) and lower HRV reliability (greater $\mathrm{CV}$ ) in individuals with greater HRV compared to individuals with low HRV $(33,34)$ further suggest that HRV reproducibility is influenced by the absolute level of HRV rather than time. Given that HRV increases from infancy to preschool age (5 years) and then decreases until adulthood (11-17 years) $(19,20)$ and beyond $(32,35,36)$, it is likely that HRV reproducibility for children may be more variable and at times poor due to the high level of HRV and autonomic modulation. Further studies should investigate the relationship between HRV reproducibility and HRV level.

Compared to previous reliability studies, the current study reported greater reproducibility (e.g., lower CV and/or lower LOA) for HRV during rest and light exercise over the 8week period $(11,18,37)$. Previous recommendations of greater control of external influences such as time of recording, overnight fast and restriction of tobacco or caffeine $(11,18,37)$ were followed in the current study and may have contributed to the greater HRV reliability compared to these prior studies. However, de- spite the greater control of these external factors, large HRV variation (e.g., CV $=3-128 \%$ ) between recordings 8 weeks apart was still demonstrated in the current study. The great variation between HRV measures was most prominent during exercise and may be a resultant of a developing and maturing autonomic nervous system with age in children $(38,39)$. Others have demonstrated this maturation process, reporting a negative and linear relationship between measures of vagal function and age $(35,36,40)$ while lower HRV was reported for both young and mature adults using protocols and HRV analysis methodology similar to those used in the current study (24).
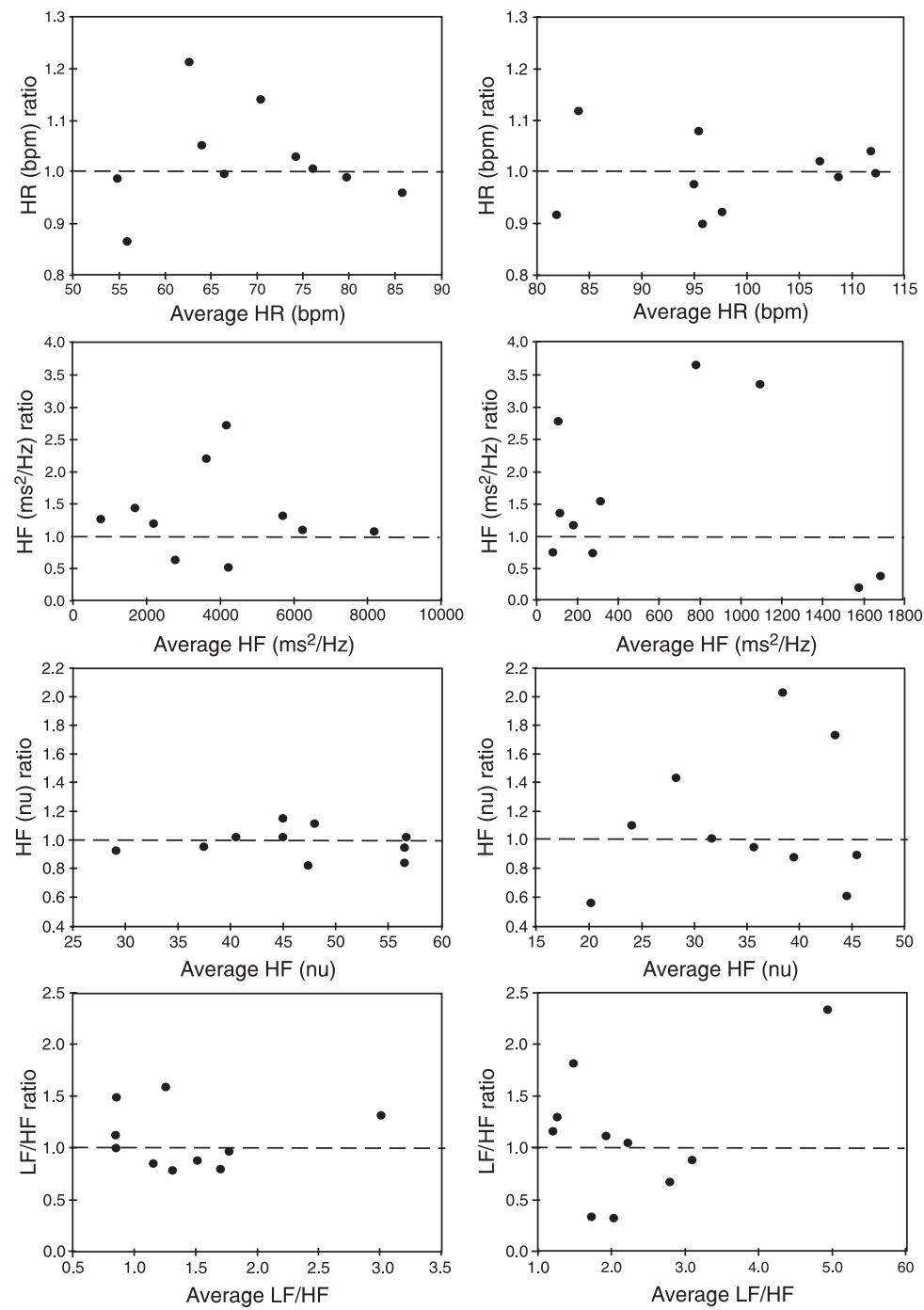

Figure 1. Ratio between the two measurements $\left(X_{1} / X_{2}\right)$ vs their mean during rest (left panels) and Ex1 (right panels). Ex1 = lowest treadmill work rate of 2 $\mathrm{km} / \mathrm{h}$ at $0 \%$ incline; $\mathrm{HR}=$ heart rate; $\mathrm{bpm}=$ beats per minute; $\mathrm{HF}=$ high frequency; nu = normalized units; LF/HF = low frequency/high frequency ratio. 
Compared to previous studies, controlling external factors during HRV recordings as done here may improve HRV reproducibility, but may not fully account for a developing nervous system during childhood.

Reproducibility measures in the current study were comparable to earlier studies as demonstrated by similar or greater ICC $(9-11,17)$ and similar or lower CV $(14,37)$. Greater reliability in the current study was most apparent for HRV measures at rest, particularly the relative measures expressed in nu (lower CV and ratio LOA). Others have confirmed this good HRV reliability at rest $(10,14$, $15,17,18,34,37)$ and greater reliability for HRV relative measures $(10,18,34)$. These results may reflect the greater control of external factors during the recording of HRV and/ or the robustness of the HRV relative measures in the present study. Further, this greater reproducibility may be a reflection of the developing parasympathetic nervous system as it influences HR control at all HRV frequencies (1), thereby minimizing changes in HRV relative measures. Regardless of the mechanism, the use of HRV relative measures in studies of children may be more applicable than HRV absolute measures due to greater reproducibility.

As previously stated, the results of the current and prior studies (18) indicate that HRV reproducibility during rest and light to moderate exercise in children is variable and may be minimized by controlling external factors. Moderate term studies examining HRV in children should therefore examine HRV changes with caution. Previous studies of $\mathrm{HRV}$ in children have examined 13-16 weeks of exercise training and reported significant HRV improvements following regular exercise training while HRV for a control

\section{References}

1. Akselrod S, Gordon D, Ubel FA, Shannon DC, Berger AC, Cohen RJ. Power spectrum analysis of heart rate fluctuation: a quantitative probe of beat-to-beat cardiovascular control. Science 1981; 213: 220-222.

2. Pomeranz B, Macaulay RJ, Caudill MA, Kutz I, Adam D, Gordon D, et al. Assessment of autonomic function in humans by heart rate spectral analysis. Am J Physiol 1985; 248: $\mathrm{H} 151-\mathrm{H} 153$.

3. Pagani M, Lombardi F, Guzzetti S, Rimoldi O, Furlan R, Pizzinelli $P$, et al. Power spectral analysis of heart rate and arterial pressure variabilities as a marker of sympatho-vagal interaction in man and conscious dog. Circ Res 1986; 59: 178-193.

4. Taylor JA, Carr DL, Myers CW, Eckberg DL. Mechanisms underlying very-low-frequency RR-interval oscillations in humans. Circulation 1998; 98: 547-555.

5. Kleiger RE, Miller JP, Bigger JT Jr, Moss AJ. Decreased group of children was largely not different $(21,22)$. These results imply that differences between groups were a result of the regular exercise training while HRV was stable over the 13- to 16-week period for the control children. However, HRV was reported to be similar over set timeframes in the current and previous studies (18) with large CV and LOA. Gutin et al. (22) commented that only some of the HRV measures were significantly improved for obese children undertaking regular exercise and that HRV changed for both obese exercise and control children, particularly the HRV measures expressed in absolute units $\left(\mathrm{ms}^{2}\right)$. These HRV improvements provide further support of an age-associated change in HRV and questionable HRV reproducibility in children.

\section{Limitations}

Although HRV reproducibility was considered to be poor in children in the current study, there are a number of limitations that should be considered. Firstly, the sample size, although similar in magnitude to other reviewed studies (8), was small. Studies incorporating a greater sample size are necessary to confirm the current results with sample size noted as an important factor when considering HRV reliability $(8,10)$. Secondly, only frequency domain HRV measures were examined in the current study, with time domain HRV measures considered to be more reliable (10). Future studies should examine time domain, frequency domain as well as non-linear HRV measures to ascertain a greater understanding of HRV and its reliability during short- and long-term recordings. heart rate variability and its association with increased mortality after acute myocardial infarction. Am J Cardiol 1987; 59: 256-262.

6. Tsuji H, Larson MG, Venditti FJ Jr, Manders ES, Evans JC, Feldman CL, et al. Impact of reduced heart rate variability on risk for cardiac events. The Framingham Heart Study. Circulation 1996; 94: 2850-2855.

7. Task Force of the European Society of Cardiology and the North American Society of Pacing and Electrophysiology. Heart rate variability: standards of measurement, physiological interpretation and clinical use. Circulation 1996; 93: 1043-1065.

8. Sandercock GR, Bromley PD, Brodie DA. The reliability of short-term measurements of heart rate variability. Int $J$ Cardiol 2005; 103: 238-247.

9. Kleiger RE, Bigger JT, Bosner MS, Chung MK, Cook JR, Rolnitzky LM, et al. Stability over time of variables measur- 
ing heart rate variability in normal subjects. $A m \mathrm{~J}$ Cardiol 1991; 68: 626-630.

10. Pinna GD, Maestri R, Torunski A, Danilowicz-Szymanowicz L, Szwoch M, La Rovere MT, et al. Heart rate variability measures: a fresh look at reliability. Clin Sci 2007; 113: 131140.

11. Amara CE, Wolfe LA. Reliability of noninvasive methods to measure cardiac autonomic function. Can J Appl Physiol 1998; 23: 396-408.

12. Bigger JT Jr, Fleiss JL, Rolnitzky LM, Steinman RC. Stability over time of heart period variability in patients with previous myocardial infarction and ventricular arrhythmias. The CAPS and ESVEM investigators. Am J Cardiol 1992; 69: 718-723.

13. Schroeder EB, Whitsel EA, Evans GW, Prineas RJ, Chambless LE, Heiss G. Repeatability of heart rate variability measures. J Electrocardiol 2004; 37: 163-172.

14. Sinnreich R, Kark JD, Friedlander $Y$, Sapoznikov D, Luria $\mathrm{MH}$. Five minute recordings of heart rate variability for population studies: repeatability and age-sex characteristics. Heart 1998; 80: 156-162.

15. Guijt AM, Sluiter JK, Frings-Dresen MH. Test-retest reliability of heart rate variability and respiration rate at rest and during light physical activity in normal subjects. Arch Med Res 2007; 38: 113-120.

16. Kowalewski MA, Urban M. Short- and long-term reproducibility of autonomic measures in supine and standing positions. Clin Sci 2004; 106: 61-66.

17. Pitzalis MV, Mastropasqua F, Massari F, Forleo C, Di Maggio M, Passantino A, et al. Short- and long-term reproducibility of time and frequency domain heart rate variability measurements in normal subjects. Cardiovasc Res 1996; 32: 226-233

18. Winsley RJ, Armstrong N, Bywater K, Fawkner SG. Reliability of heart rate variability measures at rest and during light exercise in children. Br J Sports Med 2003; 37: 550-552.

19. Goto $M$, Nagashima M, Baba R, Nagano $Y$, Yokota M, Nishibata $\mathrm{K}$, et al. Analysis of heart rate variability demonstrates effects of development on vagal modulation of heart rate in healthy children. J Pediatr 1997; 130: 725-729.

20. Heragu NP, Scott WA. Heart rate variability in healthy children and in those with congenital heart disease both before and after operation. Am J Cardiol 1999; 83: 1654-1657.

21. Mandigout S, Melin A, Fauchier L, N'Guyen LD, Courteix D, Obert $P$. Physical training increases heart rate variability in healthy prepubertal children. Eur J Clin Invest 2002; 32: 479-487.

22. Gutin B, Owens S, Slavens G, Riggs S, Treiber F. Effect of physical training on heart-period variability in obese children. J Pediatr 1997; 130: 938-943.

23. American College of Sports Medicine. ACSM's Guidelines for Exercise Testing and Prescription. 7th edn. Philadelphia: Lippincott, Williams \& Wilkins; 2006.

24. Leicht AS, Allen GD, Hoey AJ. Influence of age and moderate-intensity exercise training on heart rate variability in young and mature adults. Can J Appl Physiol 2003; 28: 446461.
25. Bloomfield DM, Magnano A, Bigger JT Jr, Rivadeneira $H$, Parides M, Steinman RC. Comparison of spontaneous vs metronome-guided breathing on assessment of vagal modulation using RR variability. Am J Physiol Heart Circ Physiol 2001; 280: H1145-H1150.

26. Patwardhan A, Evans J, Bruce E, Knapp C. Heart rate variability during sympatho-excitatory challenges: comparison between spontaneous and metronomic breathing. Integr Physiol Behav Sci 2001; 36: 109-120.

27. Leicht AS, Allen GD, Hoey AJ. Influence of intensive cycling training on heart rate variability during rest and exercise. Can J Appl Physiol 2003; 28: 898-909.

28. Bland JM, Altman DG. Statistical methods for assessing agreement between two methods of clinical measurement. Lancet 1986; 1: 307-310.

29. Hopkins WG. Measures of reliability in sports medicine and science. Sports Med 2000; 30: 1-15.

30. Nevill AM, Atkinson G. Assessing agreement between measurements recorded on a ratio scale in sports medicine and sports science. Br J Sports Med 1997; 31: 314-318.

31. Batten LA, Urbina EM, Berenson GS. Interobserver reproducibility of heart rate variability in children (the Bogalusa Heart Study). Am J Cardiol 2000; 86: 1264-1266 (A9).

32. Umetani K, Singer DH, McCraty R, Atkinson M. Twenty-four hour time domain heart rate variability and heart rate: relations to age and gender over nine decades. J Am Coll Cardiol 1998; 31: 593-601.

33. Van Hoogenhuyze D, Weinstein N, Martin GJ, Weiss JS, Schaad JW, Sahyouni XN, et al. Reproducibility and relation to mean heart rate of heart rate variability in normal subjects and in patients with congestive heart failure secondary to coronary artery disease. Am J Cardiol 1991; 68: 1668-1676.

34. Ziegler D, Piolot R, Strassburger K, Lambeck H, Dannehl K. Normal ranges and reproducibility of statistical, geometric, frequency domain, and non-linear measures of 24-hour heart rate variability. Horm Metab Res 1999; 31: 672-679.

35. Yeragani VK, Sobolewski E, Kay J, Jampala VC, Igel G. Effect of age on long-term heart rate variability. Cardiovasc Res 1997; 35: 35-42.

36. Amano M, Oida E, Moritani T. A comparative scale of autonomic function with age through the tone-entropy analysis on heart period variation. Eur J Appl Physiol 2006; 98: 276283.

37. Sandercock GR, Bromley P, Brodie DA. Reliability of three commercially available heart rate variability instruments using short-term (5-min) recordings. Clin Physiol Funct Imaging 2004; 24: 359-367.

38. Massin $M$, von Bernuth $G$. Normal ranges of heart rate variability during infancy and childhood. Pediatr Cardiol 1997; 18: 297-302.

39. Kazuma N, Otsuka K, Wakamatsu K, Shirase E, Matsuoka I. Heart rate variability in normotensive healthy children with aging. Clin Exp Hypertens 2002; 24: 83-89.

40. Ingall TJ, McLeod JG, O'Brien PC. The effect of ageing on autonomic nervous system function. Aust N Z J Med 1990; 20: $570-577$. 